\title{
Trilhas da avaliação da educação superior no Brasil: os (des)caminhos em direção ao Sinaes ${ }^{1}$
}

\section{Tracks of the evaluation of higher education in Brazil: the (dis)paths toward Sinaes}

\section{Margareth Guerra dos Santos*}

\section{Resumo}

Neste artigo, pretende-se desenhar o caminho percorrido pelas reformas na educação superior no cenário latino-americano e brasileiro, propiciando, assim, a implantação de políticas para a educação superior que visavam à criação de um sistema brasileiro de avaliação da qualidade da educação superior: o Sistema Nacional de Avaliação da Educação Superior (Sinaes). Ao percorrer esse caminho, evidenciam-se algumas questões norteadores que modificaram o panorama da oferta da educação superior no território nacional, envolvendo a inclusão de medidas consideradas mais eficazes, em uma educação superior mais produtivista, com custo baixo e que não seja questionadora. Essas reformas propiciam a entrada de concepções mercadológicas do capital financeiro, com eventos como a globalização e a mercadorização da educação superior. O contexto neoliberal das políticas voltadas para o asseguramento da qualidade da educação superior não se forma ao acaso, é, sim, resultado das pressões mercantilistas que têm no ensino superior a possibilidade de comercialização.

Palavras-chave: Mercadorização do ensino. Políticas para educação superior. Sinaes. Sistema de avaliação da qualidade da educação superior.

\section{Abstract}

This article refers to a cut of the doctoral thesis in the writing phase. The purpose of this text is to draw the path taken in the implementation of reforms for Higher Education in the Latin American and Brazilian scenario, thus fostering the implementation of policies for higher education aimed at creating a system for evaluating the quality of Brazilian higher education - The National System of Evaluation of Higher Education (Sinaes). The path of the text is followed, evidencing some guiding questions that modified the scenario of the offer of higher education in the national territory, involving the inclusion of a scenario of measures considered more effective, in a higher education productive, well managed, low cost and politically non-questioning. This scenario of reforms, propitiated the entrance market conceptions of Financial Capital, with events such as globalization and commodification of higher education. The neoliberal scenario of policies aimed at ensuring the quality of higher education is not formed by chance, but is a result of the mercantilist pressures that have the possibility of commercialization in higher education.

Keywords: Merchandising of teaching. Policies for Higher Education. Sinaes. Higher education quality assessment system.

Recebido em 10/06/2018 - Aprovado em 04/10/2018

http://dx.doi.org/10.5335/rep.v26i1.8355

Doutora em Educação pela Universidade Federal do Rio Grande do Sul. Doutora em Sociologia pela Universidade Federal do Ceará. Docente do Departamento de Educação da Universidade Federal do Amapá. E-mail: margarethguerraunifap@gmail.com 


\section{Introdução}

Este artigo é parte de um esforço analítico de problematização de políticas de controle, regulação e aferição da qualidade da educação superior. Estudar essas políticas requer uma reflexão contextualizada em cenários políticos e históricos, considerando as ações implantadas desde a metade do século XX, em especial as oriundas de pacotes de medidas - Consenso de Washington, resultante de discussões realizadas por países desenvolvidos - impostas aos países do bloco latino-americano e caribenho. As políticas que visaram à garantia da qualidade na educação superior na segunda metade do século XX resultaram na busca de uma qualidade desenhada no modelo da educação superior internacional, no âmbito da globalização hegemônica.

A globalização hegemônica produz a metáfora do conhecimento aceitável, a qual diz respeito à produção epistemológica dos que dominam o poder econômico mundial, sobrepondo aos excluídos o seu reconhecimento enquanto um possível saber local aceitável. Pensar sobre a qualidade da educação superior na bolha da globalização hegemônica, sem dúvida, é crer em outra educação superior, que se encontra distante da fronteira da identidade local ou regional. Sabe-se que a educação recebe influências de forte intensidade, sobretudo em tempos de era global, em que processos de comunicação em rede, realização de trocas de informação e conhecimento e hibridismo cultural são influências oriundas de um modelo eurocêntrico que revestem a educação superior de qualidade.

A globalização envolve nações, nacionalidades, regimes políticos, projetos nacionais, indivíduos, grupos, classes sociais, economias, sociedades, culturas e civilizações (IANNI, 2011). Globalizam-se não só a produção, a distribuição, a troca e o consumo, mas também as coisas, as gentes, as ideias, as culturas, os Estados, as instituições, desterritorializando-os e/ou reterritorializando-os, conforme seus objetivos e suas estratégias fundamentais. No horizonte da globalização, a cultura ganha dimensões globais.

Ortiz (2000), sem a pretensão de conceituar cultura, define-a, de modo preliminar, como um campo de domínio dos símbolos, pois o símbolo tem a capacidade de apreender e relacionar as coisas. No campo da cultura, o homem é um ser simbólico, e a linguagem é um dos utensílios indispensáveis que definem sua humanidade. Toda a sociedade compõe uma cultura, e são esses universos simbólicos que caracterizam as coisas, constituindo-se em diversas visões de mundo.

A correlação entre cultura e economia não se faz, portanto, de maneira imediata. Isso significa que a história cultural das sociedades capitalistas não se confunde com as estruturas permanentes do capitalismo, ou seja, "[...] cultura é o sistema-i- 
deia desta economia capitalista mundial, a consequência de nossas tentativas, coletivas e histórias, em nos relacionarmos com as contradições, as ambiguidades, e a complexidade da realidade sociopolítica desse sistema particular" (ORTIZ, 2000, p. 26).

Uma cultura mundializada não implica o aniquilamento das outras manifestações culturais; ela coabita e se alimenta delas (ORTIZ, 2000); não aniquila no sentido de reverenciar, preservar, mas, sim, a partir de uma visão colonialista, de transformá-la em bem de consumo, visando ao lucro. Podem culturas diferentes conversar entre si, sem que uma se sobreponha a outra? Acredita-se que culturas e identidades podem vir a ser "engolidas" por uma cultura receptora e "digeridas", de forma tal a se adaptarem a todo o universo simbólico de uma coletividade. Tal observação é percebida no contexto socioeconômico em que nos encontramos, pois, a cada semana, novos padrões de consumo de bens materiais são postos em vigência, por meio de bens de pouquíssima - ou até mesmo, nenhuma - utilidade.

Pensar sobre as políticas de avaliação da qualidade da educação superior, no sentido da era global, pressupõe revelar, logo, nesta apresentação, nossa inquietação inicial, que conduz a uma questão estruturante: os indicadores de qualidade pensados no Sistema Nacional de Avaliação da Educação Superior (Sinaes) estão centrados em modelos externos ao nosso país, à Região Norte e aos contextos locais, em um processo de padronização atrelado a símbolos de uma qualidade presente em nações e culturas supostamente mais "desenvolvidas". Instigamo-nos a pensar sobre o quanto tal procedimento é afetado por resquícios de uma visão colonizadora de educação, permeada por uma lógica passível de manifestar-se de modo etnocêntrico.

Em um esforço para elaborar um estudo acerca do Sinaes no Brasil, é importante contextualizar o panorama das condições de inserção de políticas de controle da qualidade da educação superior no mundo globalizado e capitalista, seus impactos nas políticas para a qualidade da educação superior na América Latina e no Caribe, em especial no Brasil. Para tanto, propõe-se refletir sobre o cenário da educação superior pós-1960, destacando as trilhas na direção do Sinaes.

\section{0 cenário da educação superior no Brasil: o pós-1960}

O cenário da educação superior no Brasil, no século XX, é marcado por um quadro de reformas - Reforma Universitária de 1968 -, que significou a adoção de medidas de transformação na organização administrativa e acadêmica das universidades. Rosas (1992) comenta que, no início dos anos 1960, a educação superior brasileira passou por uma avaliação cujo resultado classificou-a como insatisfa- 
tória, em especial a sua estrutura. Assim, um debate nacional, que antecedeu a promulgação da Lei de Diretrizes e Bases da Educação Nacional de 1961, estimulou um conjunto de novas ideias para a educação superior no Brasil. Destacamos, nesse contexto de proposições, a assinatura da Carta de Punta del Este, ${ }^{2}$ a qual estabelecia que, a partir de sua assinatura, em 17 de agosto de 1961, os países consignatários do acordo deveriam implantar reformas, incluindo Políticas de Educação Superior. A assinatura desse documento pretendeu superar o excesso de nacionalismo dos países consignatários sob a tutela dos Estados Unidos da América (EUA), implantando uma política comum de desenvolvimento, com investimentos e programas multinacionais, sob a lógica dos EUA e seu apoio técnico e financeiro.

Em um artigo recente, em histórico escrito para lembrar os 55 anos dessa carta, Dario do Carmo da Rocha escreve:

Dando sequência na análise sobre o desenvolvimento econômico proposto na Carta de Punta del Este, encontram-se definidas as pré-condições para o processo de acumulação de capital, onde a educação teria o papel fundamental, treinando mestres, técnicos e especialistas. Proviu também, treinamento acelerado aos operários e camponeses e ofereceu programas de escolarização em massa para melhorar os índices de escolaridade no país (2016, não paginado).

A assinatura da Carta de Punta del Este pelo governo brasileiro impunha a necessidade de estabelecer um programa de reformas, em especial para a educação superior, mas o teor do documento também fazia referência a um conjunto de medidas a serem tomadas em diversas áreas: segurança, educação, saúde e bem-estar social. Não nos propomos a analisar essa carta, mas julgamos interessante destacar seu ideário de necessária efetivação do capital, tendo à frente os EUA. Aos países latino-americanos e caribenhos foi imposto um modelo concentrador de renda, o qual trazia, como discurso, o apoio técnico para o desenvolvimento social e econômico desses países.

Com o objetivo de atingir as metas elucidadas em uma suposta aliança para o progresso, a carta mencionada efetiva os primeiros passos para um conjunto de reformas em diversas áreas, incluindo a educação superior, nos países latino-americanos e caribenhos. Concomitante a esse cenário, regimes militares se instalaram nos países latino-americanos, em especial da América do Sul, sob a bandeira do "desenvolvimento para o progresso", e em governos de países consignatários da Carta de Punta del Este.

O quadro que se definiu, no pós-1960, na América Latina, em especial no Brasil, foi o de regimes militares instalados pela força, na grande maioria dos países pertencentes ao bloco. Ainda, sob a tutela das medidas acordadas na Carta de Punta del Este, acordos de cooperação técnica e financeira foram firmados entre os 
países latino-americanos e caribenhos com agências e órgãos norte-americanos. É importante frisar que esses acordos significaram, para esses países, a penetração norte-americana em seus governos e também de indústrias multinacionais para a exploração de recursos naturais, produção de bens de consumo e a importação de tecnologia, que presumiu a introdução da influência norte-americana em diversas áreas. Na área educacional, no Brasil, foram realizados convênios entre os organismos de gerência da educação nacional e o órgão norte-americano United States Agency for International Development (Usaid) - Agência dos Estados Unidos para o Desenvolvimento Internacional.

Com o advento do golpe de 1964, no Brasil, reformas de base foram contidas a Democratização da Universidade estava na agenda. Um cenário de contradição na dinâmica das universidades instalou-se com a tomada, por parte do governo, de medidas controladoras das instituições públicas de ensino superior no Brasil, para além dos financiamentos, suas estruturas internas (organizacionais), centralização da gestão e avaliação burocrática de seus planos de trabalho para aprovação. O papel da Usaid era o de assessorar os países, no caso o Brasil, para reformar e modernizar a administração; em relação à educação, a Usaid passou a efetivar o planejamento da educação nacional em todos os níveis, incluindo legislação, planejamento e execução, assegurando um controle científico e didático do Sistema Nacional de Educação.

A Reforma Universitária de 1968 tinha, então, seus elementos consubstanciados nas medidas para educação superior contidas no acordo firmado na Carta de Punta del Este, nos manuais oriundos do acordo entre Ministério da Educação (MEC) e Usaid, no Brasil, e nos estudos do professor Rudolph P. Atcon:3 Rumo à reformulação estrutural da universidade brasileira, publicado no ano de 1966 . O professor Atcon passou a figurar na lista de consultores do MEC, para propor medidas efetivas para o processo de reforma estrutural da universidade brasileira (ROSAS, 1992). Em julho de 1968, foi criado, no governo do regime militar do presidente Costa e Silva, o Grupo de Trabalho da Reforma Universitária (GRTU) (BOSCHETTI, 2007). Esse grupo utilizou como referencial um conjunto de estudos, conhecido na literatura da reforma da educação superior como Plano Atcon, que, segundo Boschetti, definia “[...] a emergência dessa nova universidade, e seria fator de eficiência e produtividade adequadas à ideologia pós-64: nacionalismo desenvolvimentista e reconstrucionista" (2007, p. 225). O Plano Atcon traduziria uma nova universidade, a reformada.

Nesse contexto, surgiu a reforma universitária - com a Lei no 5.540/1968, implementada nos moldes da centralização do governo militar, que significou a valorização da racionalidade, do tecnicismo, da produtividade e de outros elementos 
presentes na administração desejada pelas empresas. O regime militar representou a consolidação de um cenário marcado pelo capitalismo tardio no Brasil, o qual impulsionou o desenvolvimento de um parque industrial que tinha suas bases no mercado cultural. Interesses dos capitalistas da indústria dos bens culturais e dos militares convergiram para a construção de uma integração nacional. Ortiz (2000) esboça questões como a dimensão política de repressão, censura, prisões e exílio, contrapondo-se a um fortalecimento do parque industrial de produção de cultura e de bens culturais, as quais se elegem, dentro do trabalho de Ortiz, como pontos de contradição, mas que passaram a conviver nesse cenário de mundialização do capital.

Ao ser estabelecida, a cultura do mercado de consumo moderna e massificada vai ao encontro dos interesses de um governo militar autoritário e de empresários mercadológicos. Nesse cenário, a universidade passa a funcionar com um organograma empresarial, preocupando-se com a ordem socioeconômica dos governos militares e do capital internacional. Para Boschetti (2007), a universidade passou a ser organizada nos moldes da empresa capitalista, produzindo distinções entre quem executa e quem planeja. Concordamos com Boschetti sobre o que significou a reforma universitária de 1968:

A Reforma partiu do princípio de que o ensino superior é uma necessidade social: não uma necessidade em si, símbolo do progresso e da cultura a serviço do ser humano, mas um meio que permitiria avançar na condição de espaço periférico para a condição de espaço central, como nos modelos estrangeiros. Para tanto, reestruturou conteúdos e cursos com o intuito de trazer o recém-formado para um mercado de trabalho que estaria a sua espera não apenas para realizar seu sucesso profissional, mas também para integrá-lo ao movimento nacionalista de projetar o Brasil (BOSCHETTI, 2007, p. 228).

A proposta da reforma universitária trouxe à discussão a necessária redefinição da educação superior no Brasil, uma definição com conceitos ligados à empresa privada, de rendimentos e produtividade, consolidando a ideia do negócio lucrativo. As tendências a favor da privatização da oferta do ensino superior, por ocasião da reforma universitária, vinham ganhando fôlego no cenário internacional, chegando ao Brasil por intermédio das discussões oriundas da necessidade de modernização da educação superior brasileira.

Cabe lançar um olhar sobre a educação superior latino-americana pós-reforma. Guadilla (2002) relata que o quadro de reformas implantadas nas Políticas para Educação Superior na América Latina reflete a perda real de autonomia proveniente da gestão de regimes militares, em sua grande maioria, na implantação das reformas, mesmo havendo um discurso acerca da autonomia universitária das instituições públicas de ensino superior. Apesar desses discursos, presentes nas raízes das reformas implantadas, as reformas universitárias em solo latino-ame- 
ricano significaram a mercantilização, ou seja, o processo de adensamento de uma cultura mercantil nas políticas para educação superior. A ideia de mercantilização passou a configurar a ideia de reforma da educação superior, mesmo após a abertura da política nos países regidos por regimes militares, nesse caso, o Brasil - em 1979.

Com o advento da democratização do país, discursos em prol das liberdades política e ideológica passaram a se configurar no cenário da definição política do país. Um forte discurso em prol da educação pública de qualidade tomou conta das reivindicações dos especialistas, em especial da educação. Porém, mesmo nesse cenário de liberdade, democratização e luta por uma educação pública de qualidade, o processo de mercantilização tomou o rumo das políticas para educação superior, criando-se um cenário de desconforto. Crises financeiras passaram a fazer parte das agendas dos governos, gerando um cenário de insatisfação social. Com um olhar voltado para as crises nos países latino-americanos, incluindo o Brasil, os países desenvolvidos, capitalistas, em especial os EUA e a Inglaterra, com o intuito de produzir estudos que visassem propor medidas de ajustes, propuseram um pacote de medidas, em uma reunião intitulada Latin American Adjustmente: how much has happened, conhecida como o Consenso de Washington.

A reunião de Washington (em 1989) resultou em um pacote de medidas que significariam mudanças nas formas de administrar dos governos dos países em estado de pobreza pós-crises internas. As mudanças atingiriam os gastos públicos com saúde, educação e previdência, proporcionando, em teoria, um alívio aos cofres públicos. Amaral (2003) destaca que essa reunião revelou um discurso disfarçado pela preocupação em eliminar a pobreza. Porém, não se discutiram assuntos relacionados à preocupação com educação, saúde, distribuição de renda ou eliminação da pobreza. Em verdade, foram apresentadas medidas em torno das áreas: 1. Disciplina fiscal; 2. Priorização dos gastos públicos; 3. Reforma tributária; 4. Liberalização financeira; 5 . Regime cambial; 6. Liberalização financeira; 7. Investimento direto estrangeiro; 8. Privatização; 9. Desregulação; e 10. Propriedade intelectual (AMARAL, 2003, p. 47).

Essa política, em relação à educação, criou uma série de reformas, que conduziram esse nível de ensino a mercantilizar ${ }^{4}$ sua oferta privada. O cenário da década de 1990 passou a configurar o aumento do número de instituições de ensino superior privadas. Alguns especialistas destacam que, na América Latina, teria ocorrido uma segunda reforma no século XX, na qual o foco teria sido a mercantilização da educação superior. O Brasil não escapou dessas transformações e passou a adotar uma política de disciplina fiscal, dando início a uma escala de privatizações de empresas estatais, abrindo espaço para a iniciativa privada. As políticas de 
governo, no Brasil, dedicaram-se a criar condições para o acesso à rede privada de educação superior, produzindo um clima favorável por meio de discursos:

A defesa da maior diversificação das instituições de ensino superior teria por base três análises principais, pela ótica do financiamento: 1. A universidade de pesquisa (modelo humboldtiano) é de alto custo; 2 . As instituições não universitárias contribuiriam para atender à demanda crescente por educação superior a um custo muito baixo; 3 . A expansão do setor privado provocaria uma melhor adequação do sistema de educação superior às exigências do quase-mercado educacional, além de se efetivar a um custo muito mais baixo para o Fundo Público (AMARAL, 2003, p. 93, grifo nosso).

Surge, então, um novo cenário na gestão dos governos dos países consignatários da adesão desse pacote, um novo modo operante sinalizado pelas decisões emanadas de organismos internacionais de financiamento, destacando-se o Fundo Monetário Internacional (FMI), o Banco Mundial (BM) e a Organização Mundial do Comércio (OMC), sob o controle dos países desenvolvidos. Para os latinos, havia a crença de que essa adesão simbolizava possibilidades de superar as crises que seus países vinham vivenciando nos pós-regimes militares.

Alguns especialistas, como Amaral (2003), destacam que, no caso brasileiro, o período pós-Constituição de 1988 foi marcado por mudanças na educação superior como reflexo de um pensamento único mundial, que, entre outras questões, tencionava estabelecer uma linha de ação pautada na ampliação das instituições privadas e na implantação de outras fontes de financiamento, estabelecendo o que Amaral (2003) designa como um "quase-mercado educacional", ${ }^{5}$ em que a oferta atenderia à demanda que se expandia no número de matrículas. A década de 1990 foi considerada o auge do quase-mercado da educação superior.

Com a falência do ensino técnico e a tendência de o processo globalizador demandar profissionais qualificados em nível superior, o acesso à educação superior foi incentivado por segmentos do mundo do trabalho. $\mathrm{O}$ novo perfil do profissional imposto pela economia globalizante impulsionou a expansão de novas instituições privadas de ensino superior, criando um mercado lucrativo e promissor. A qualificação do profissional voltou-se exclusivamente para o mercado, atendendo demandas específicas; a qualificação pretendida produziu uma qualificação com características desqualificantes (ALVES, 1999).

Acrescentamos a essa discussão a teoria de Theodoro Schultz ${ }^{6}$ (BROOKE, 2012) - a teoria do capital humano -, que alavancou o que Brooke denomina de "[...] nova indústria de planejamento educacional comandada por economistas, além de uma gama de assessores e de especialistas" (2012, p. 55). Um período de expansão do sistema educacional, em especial o da educação superior, estabeleceu-se sob a forte influência de agências de desenvolvimento internacional e bancos 
multilaterais. A educação superior passou a ser, então, considerada um segmento lucrativo para o mercado, atraindo investimentos de empresas privadas.

Frigotto, ${ }^{7}$ em sua obra sobre teoria do capital humano, enuncia: "[...] a questão básica é, pois, como e que tipo de educação é gerador de diferentes capacidades de trabalho e, por extensão, da produtividade e da renda. Potencialização do trabalho põem em cheque o que a educação realmente preocupa-se" (2003, p. 55, grifo nosso). Abre-se uma chave de leitura para destacar o fato de a "teoria do capital humano" ter influenciado um tipo de educação subordinada ao grande capital, com reflexos, no Brasil, no período de 1968 a 1975, mediante produções efetivas nas diretrizes da "Reforma Universitária de 1968 e, sobretudo, a Lei de Diretrizes e Bases da Educação Nacional, de 1971, corporificam a essência deste ajuste" (FRIGOTTO, 2003, p. 43).

A teoria do capital humano influenciou as políticas de organismos multilaterais, como o BM, o FMI, dentre outros, sendo determinante na configuração da educação superior nos anos 1990. Os impactos desse modelo que pregava o discurso da modernidade em defesa de uma educação de qualidade, em que as categorias “[...] flexibilidade, participação, trabalho em equipe, competência, competitividade e qualidade total" (FRIGOTTO, 2003, p. 55), estariam a configurar na perspectiva da sociedade do conhecimento.

Frigotto discorre sobre o cenário em que se configuram as políticas:

O resultado deste processo de intensa acumulação, particularmente nos países capitalistas centrais, foi um profundo revolucionamento da base técnica do processo produtivo (Terceira Revolução Industrial), com impactos, positivos e negativos sobre o trabalho humano. Configuram-se uma nova divisão, mudança no conteúdo, quantidade e qualidade do trabalho e novas demandas de qualificação humana (2003, p. 60).

Seguindo a análise de Amaral (2003), as políticas para o desinvestimento na educação superior pública tornaram-se inevitáveis e muitos argumentos conduziam Estados ao que Boaventura de Sousa Santos (2008a) denomina projeto global de política universitária, em que havia o desinvestimento do Estado na universidade pública e a globalização mercantil do ensino superior. A universidade no século $\mathrm{XX}$ entrou em uma fase de contradições, pois nela eram depositadas aspirações do mundo do capital, mas, ao contrário de investimentos, promovia-se um desinvestimento na instituição, o que Sousa Santos (2008a) denomina de crise pela qual passava a instituição ao entrar no século XXI. A crise configurava-se em um processo de mercantilização impulsionado pela globalização hegemônica. Esse processo de mudanças decorrentes de um processo de mercantilização ${ }^{8}$ (RAMA, 2006) impôs uma terceira reforma na educação superior latino-americana e, consequentemen- 
te, na brasileira: a necessidade de políticas para assegurar a qualidade do ensino superior, que havia se expandido sem controle.

Brovetto destaca que as medidas na área da educação, em especial no ensino superior, promoveram um movimento assim traduzido pelo autor:

As características dominantes do ensino superior na América Latina e no Caribe, descritas anteriormente, não se originaram de forma espontânea, mas responderam a um conjunto de decisões políticas articuladas entre si e baseadas na ideia de que a educação superior não deve ocupar um espaço de atenção prioritária, em muitos países em via de desenvolvimento, na medida em que ainda não se obteve, nos graus fundamental e médio, um acesso geral adequado, nem níveis satisfatórios de qualidade de vida e equidade. Por este motivo, favoreceu-se, por um lado a redução de gastos públicos no âmbito do ensino superior e, por outro lado, o desenvolvimento de instituições privadas, com o objetivo explícito de adaptar o conjunto do sistema às necessidades mutáveis do mercado de trabalho [...] (2002, p. 349-350).

O fim do século XX foi marcado pela lógica especulativa e transformadora do capital, em que a produção de mercadorias transforma espaços e impõe aceleração da vida humana (HARVEY, 2014). A lógica mercantil conduz à mercadorização da educação, e o discurso da preparação profissional insere-se nas políticas para a educação superior. Um novo movimento se instala com o objetivo de derrubar fronteiras - a globalização - e com ele a expansão da oferta da educação superior nas mãos da iniciativa privada; esse movimento passou a ser denominado economização da educação (SOBRINHO, 2000).

\section{Os paradigmas da educação superior no limiar do século XXI: rumo à avaliação da qualidade}

O limiar no século XXI produz uma virada, novas técnicas, novos conhecimentos, novas ideologias que traduzem uma ação humana mundializada - a globalização. Milton Santos (2015) considera o fenômeno da globalização o ápice do processo de internacionalização do mundo capitalista, produzindo novas relações em uma aldeia global, um capitalismo hegemônico - globalização hegemônica, em que as peculiaridades regionais ou locais ficaram reduzidas.

A globalização hegemônica se produziu na base de forte discurso de homogeneização, com princípios de mercado impondo aos Estados nacionais a financeirização da economia. Dentro desse quadro que se volta às políticas de governo, as direcionadas à educação superior se expressam em direção da expansão da oferta privada, preparação do profissional para o mercado de trabalho e da internacionalização - educação para além da fronteira. Porém, em relação à educação superior, a universidade latino-americana e caribenha, em especial a brasileira, está 
estruturada para atender à demanda do mundo globalizado. Nesse sentido, Rama (2006) comenta que uma terceira reforma estaria a ser anunciada, diante do novo cenário tecnológico e da competitividade econômica, exigindo um novo perfil de universidade:

MODELO EDUCATIVO: Internacionalização na Universidade da diversidade do modelo trinário do público-privado e do nacional-internacional; MODELO POLÍTICO: lógica nacional, Sistemas de asseguramento da qualidade e associações de reitores; OBJETIVOS POLÍTICOS: Busca de regulação pública, Remoralização universitária: a educação como bem público e Estado Avaliador; INSTRUMENTOS: Educação transnacional, Alianças internacionais e flexibilização institucional (RAMA, 2006, p. 144, traduação nossa).

O cenário da educação superior que se estende da América Latina ao Brasil refere-se a um movimento de mudanças na dinâmica do ensino superior, com o propósito de adequar as políticas próprias ao modelo globalizado de mercado, em que o conhecimento volta-se para a lógica da produtividade, da formação profissional. O conhecimento passa a ser considerado mercadoria com valor, conforme destaca Harvey acerca da mercadorização do conhecimento:

O acesso ao conhecimento científico e técnico sempre teve importância na luta competitiva; mas, também aqui, podemos ver uma renovação de interesses e de ênfase, já que, num mundo de rápidas mudanças de gostos e necessidades e de sistemas de produção flexíveis (em oposição ao mundo relativamente estável do fordismo padronizado), o conhecimento da última técnica, do mais novo produto, da mais recente descoberta científica, implica a possibilidade de alcançar uma importante vantagem competitiva. O próprio saber se torna uma mercadoria-chave, a ser produzida e vendida a quem pagar mais, sob condições que são elas mesmas cada vez mais organizadas em bases competitivas [...] (HARVEY, 2014, p. 151).

O conhecimento passou a ter papel definitivo, como elemento que marcou o desenvolvimento das sociedades capitalistas, e quanto maior o domínio do conhecimento maior a representatividade do país. O novo século trouxe novos desafios para a educação superior - a capitalização do conhecimento. Em relação à capitalização do conhecimento pode-se dizer que as políticas para a educação, em especial, neste estudo, as voltadas à educação superior, tinham suas diretrizes traçadas pelos interesses econômicos - tendência do século XXI, movida pela globalização econômica -, definindo um escopo de domínio da privatização, na qual o espaço público viu-se invadido pela política de acumulação capitalista - a venda da mercadoria conhecimento profissional.

A universidade passou a ser questionada pelo capitalismo, e o papel dela passou a ser o de produtora de mão de obra qualificada, e o ensino técnico da década de 1960 tornou-se o ensino universitário da virada do século XX para o XXI. Nos anos 2000, a visão economicista do capitalismo, disfarçado pelos apelos da globalização, transformou a educação superior em produtora de capital - humano, político e 
intelectual. Bourdieu traz um discussão interessante acerca do campo do poder em que se inserem os tipos de capital:

O campo do poder (que não deve ser confundido com o campo político) não é um campo como os outros: ele é o espaço de relações de força entre os diferentes tipos de capital ou, mais precisamente, entre os agentes suficientemente providos de um dos diferentes tipos de capital para poderem dominar o campo correspondente e cujas lutas se intensificam sempre que o valor relativo dos diferentes tipos de capital é posto em questão [...] (2011, p. 52).

O capital intelectual tem sido considerado, na linguagem do BM, o capital de alto nível, produzido, em especial, em universidades, faculdades e outras formas de instituições de ensino superior (IES), com a intenção de produzir mão de obra de qualidade para ser inserida na sociedade globalizada do mercado de trabalho; uma sociedade que priorizava o domínio da alta tecnologia, dos meios de comunicação e do conhecimento - capital intelectual. No entendimento dos protagonistas da educação superior, surgiu um novo discurso; uma nova educação superior foi desafiada a emergir, em especial nos países na América Latina e do Caribe, com o objetivo de produzir conhecimento que desenvolvesse um profissional adequado à cultura empresarial - capital humano. Em contraposição a essa expectativa, a educação superior latino-americana e caribenha apresentou um cenário de baixos investimentos na pesquisa e com quase nenhum avanço tecnológico.

Esse cenário latino-americano da educação superior provou ser incapaz de atender à demanda do setor produtivo, estabelecida também pelo que se denominou "brecha digital e cognitiva" (UNESCO, 2005). Um mercado de oferta da educação superior, dominado pela lógica mercantil, tomou conta da educação superior, e um "novo imperialismo hegemônico" centrou-se no conhecimento e na informação. As IES passaram a ocupar lugar de visibilidade e cobiça por parte de um mercado voltado para o capital intelectual e humano.

$\mathrm{O}$ movimento em direção à mercadorização da educação superior, em especial nos anos 2000, trouxe um recorte diferente do que ocorreu no século passado, um movimento de convencimento aportado em uma lógica de “[...] um novo imperialismo, na sua forma benevolente, está a se constituir tendo a Europa do conhecimento como centro hegemônico e a América Latina como centro subordinado" (LEITE; GENRO, 2012, p. 77). Segundo Leite e Genro (2012), o processo de mercadorização da educação superior refletiu a formação de um intelectual capitalista, um homem de negócios, sujeito em articulação e inserido no mundo global.

Na articulação com esse mundo global, as políticas para educação superior são ressignificadas, nessa terceira onda do imperialismo (LEITE; GENRO, 2012), são priorizadas reformulações curriculares e avaliações institucionais, associando-se como parte de um pacote de ideais da globalização hegemônica. Para Boaventura 
de Sousa Santos (2008a), a universidade confronta-se com essa globalização, pois lhes são imputadas exigências provenientes da sociedade do conhecimento. No entanto, cada vez mais são adotadas medidas restritivas ao seu financiamento por parte do Estado. Diante da necessidade de implantar uma política de formação de um homem de negócios, a expansão da educação superior via iniciativa privada vinha tomando proporções significativas nos números de matrículas. Esse dado marca, em definitivo, a urgência das políticas de asseguramento da qualidade, de forma internacional.

Em paralelo a esse contexto de expansão da oferta da educação superior, cresce a produção de uma epistemologia da crença em saber globalizante e hegemônico, que serviria como parâmetro de qualidade para as políticas de asseguramento na educação superior. Boaventura de Sousa Santos circunscreve esse cenário da seguinte forma:

[...] a atual reorganização global da economia capitalista assenta, entre outras coisas, na produção contínua e persistente de uma diferença epistemológica, que não reconhece a existência, em pé de igualdade, de outros saberes, e que por isso se constitui, de fato, em hierarquia epistemológica, geradora de marginalizações, silenciamentos, exclusões ou liquidações de outros conhecimentos (SOUSA SANTOS, 2008b, p. 153).

A questão que se revela é a concepção de um conhecimento aceitável sob a lógica do capital - paradigma dominante (SOUSA SANTOS, 2008c), um conhecimento universitário a serviço do mercado, estando à disposição de quem domina os recursos financeiros. Diante dessa relação de dependência com o capital, o conhecimento universitário passa a ser objeto de um mercado em crescente ascensão economia do conhecimento. Sob a lógica da economia do conhecimento, a produção do capital humano passa a ser estruturada em uma lógica produtivista voltada para o mercado, com formação humana, pesquisa e inovação tecnológica visando às necessidades do mercado capitalista.

A educação superior passa a se configurar como um serviço na lista da OMC, ${ }^{9}$ configurando uma nova dinâmica de oferta da educação superior voltada à produção de insumos para o mercado com geração de lucros. Assim, mercados de prestação de serviços educacionais surgem; a inclusão da lógica empresarial vincula-se à oferta da educação superior; o capital internacional elimina as fronteiras e adentra nos serviços educacionais, em especial na educação superior.

Uma tendência produtivista, com base em conceitos de eficiência, qualidade e prestação de contas, passa a fundamentar as políticas para a educação superior, em níveis tanto internacionais quanto regionais e locais. $\mathrm{O}$ interesse da maioria da sociedade passa a ser desvinculado sob o disfarce da necessária adequação aos valores da sociedade do conhecimento. Com a expansão da educação superior - 
privatização da oferta -, temas como qualidade passam a alcançar destaque nas discussões internacionais, reunindo organismos governamentais, não governamentais e de especialistas na área da educação superior. Destacamos a Conferência Mundial sobre a Educação Superior (1995), que resultou em um documento referência ${ }^{10}$ na virada do milênio, o qual definiu diretrizes para discutir qualidade e o seu reconhecimento - selo internacional. As discussões convergiram para a necessidade de garantir o asseguramento da qualidade, assim, a temática avançou e é possível identificar um movimento de agências de avaliação da qualidade que surgiram ainda nos anos 1990, algumas com estrutura de organismos financeiros que passaram a financiar o seu desenvolvimento. Nesse sentido, podemos elencar o surgimento da International Network for Quality Assurance Agencies in Higer Education (INQAAHE), ${ }^{11}$ uma rede internacional de agências nacionais de acreditação e avaliação da qualidade da educação superior, tendo como referência os países do continente europeu.

Os conceitos de acreditação e avaliação tornaram-se pontos de convergência e de interesses entre as agências nacionais. Leite define os conceitos:

Acreditação: processos externos de revisão de qualidade empregado para examinar em profundidade os colleges, as Universidades e os programas de educação superior, visando à garantia e desenvolvimento da qualidade, resultante do mesmo, uma Acreditedinstitution (EUA) ou Recognizedbodies (UK) (2006, p. 490).

Avaliação da Educação Superior: designa a avaliação que tem por objeto a supervisão e o controle do sistema de educação superior no seu conjunto e de cada uma das instituições e programas e políticas que o constituem (2006, p. 462).

Com a implantação de sistemas de agências públicas ou privadas voltadas à normatização de um conjunto de mecanismos direcionados à supervisão e ao controle do Sistema da Educação Superior, muitas tendências passaram a se revelar no estado da arte da avaliação da qualidade dessa modalidade de ensino. O documento-base da Conferência Regional para Educação Superior na América Latina e Caribe (Cres) ${ }^{12}$ de 2008 destaca o discurso preocupado dos representantes dos países participantes com a ambiguidade de concepções dos sistemas de agências de avaliação da qualidade da educação superior.

Essas concepções, no modelo adotado pelas políticas de países desenvolvidos, têm a prevalência de aceitação de modelos importados de países considerados desenvolvidos e com conhecimento reconhecido na área da educação superior. É possível observar os modelos de educação superior que são considerados de qualidade internacionalmente reconhecida. Leite e Genro (2012), ao se referirem a um "imperialismo sutil e benevolente", refletem sobre um movimento que tem apresentado 
uma política internacional baseada no modelo europeu do processo de Bolonha, ${ }^{13}$ em que um dos pontos de destaque é a cooperação europeia para a garantia da qualidade da oferta da educação superior. Esse processo de garantia de qualidade é parte do projeto de globalização da educação superior no século XXI.

Políticas voltadas à criação de sistemas nacionais de avaliação passam a ser incorporadas pelos países latino-americanos e caribenhos - neste estudo, destaca-se o Brasil -, nos moldes ocorridos no continente europeu e no âmbito dos EUA, na busca pelo asseguramento da qualidade da oferta do ensino em tempos de globalização e expansão da oferta.

Os modelos que se apresentam na concepção dos sistemas nacionais de avaliação da qualidade, seguem, segundo Contera (2002), uma ambiguidade que reflete as tendências que os sistemas assumem no contexto da globalização hegemônica; uma tendência ao modelo regulatório caracterizada pelo interesse no caráter técnico da avaliação, com enfoque quantitativo e de prestação de contas (Accountability), com processos na linha ética competitiva, com indicadores de rendimento baseados na racionalidade instrumental. Essa tendência tem caracterizado o perfil dos sistemas nacionais de avaliação da qualidade da educação superior.

Leite cita a seguinte preocupação: “[...] a avaliação que poderia estar a serviço da reforma e construção do compromisso com a democracia passa a ser o instrumento de centralização da homogeneização e do controle" (2003, p. 65). Sob a tutela do sistema de regulação da qualidade do ensino superior, tendo como referência critérios mercadológicos de qualidade, a avaliação passa a ser instrumento do mercado mundial, em que, para figurar no campo da oferta do ensino, os critérios estabelecidos com base nesse mercado deveriam estar consolidados na dimensão didático-pedagógica, na formação e qualificação do corpo docente e na estrutura física.

\section{Ponto de partida da implantação das políticas de avaliação da qualidade da educação superior: caso brasileiro}

Com o advento da criação das agências, passaram a vigorar normas, termos e mecanismos diversos, mas com um objetivo comum: a avaliação e a acreditação da qualidade da educação superior. A preocupação de tais agências era a de dar reconhecimento à qualidade da educação superior ofertada em seus países. Diante do quadro que se instalou em todos os continentes, ganhou palco a discussão acerca da qualidade da oferta da educação superior. É nesse cenário que o governo brasileiro inseriu, em suas políticas, medidas para a avaliação da qualidade da educação superior. 
A avaliação pode favorecer a compreensão coletiva sobre as qualidades positivas, pontos fortes, aspectos em que a instituição se autorreconhece melhor que as outras. Permite revisar falhas, os erros, e também, e o que é mais importante - definir prioridades para a gestão democrática da universidade (LEITE, 2003, p. 29).

No Brasil, ainda em meados do século XX, em 1976, um grupo de especialistas propôs discutir a avaliação da qualidade. E, em um momento político marcado pela fragilidade do sistema governamental, instalou-se o $1^{\circ}$ Seminário Internacional de Avaliação, organizado pela Universidade de Campinas (Unicamp), inaugurando um novo momento nas discussões sobre o processo avaliativo da educação superior no Brasil, com o surgimento do Programa de Apoio ao Desenvolvimento da Educação Superior.

A Universidade Brasileira vem de um período caracterizado, sobretudo, pela década de 70, em que a política equivocada do governo federal provocou seu crescimento desordenado e agravou seu estado de crise e perplexidade. De um período mais longo, deflagrado com o golpe de 1964, em que a política oficial para a educação superior sufocou quase toda a sua criatividade, na medida em que exerceu rígido controle sobre seu financiamento, sua estrutura interna e organização, seus projetos acadêmicos, seu pensamento (ROSAS, 1992, p. 21).

Nesse período, também houve a vivência de políticas avaliativas no campo da pós-graduação, com a criação da Capes. Isso reforçou a necessidade de estudos em torno da avaliação como elemento dinamizador das políticas educacionais na educação superior, que avançou decisivamente a partir da década de 1980, quando, segundo relato do próprio Instituto Nacional de Estudos e Pesquisas Educacionais Anísio Teixeira (Inep), ainda havia poucos estudos no âmbito da avaliação institucional e da educação superior. No entanto, com o crescente interesse do governo em implementar reformas na educação superior, surgiu a primeira proposta de avaliação desse segmento no país: o Programa de Avaliação da Reforma Universitária (Paru), em 1983. Esse programa aplicou questionários no âmbito da comunidade universitária, com o objetivo de verificar o impacto da Lei n⿳ 5.540/1968 - Reforma Universitária de 1968 (INEP, 2009).

Com a promulgação da Lei no $9.131 / 1995$, que deu as bases da sistemática de avaliação, o governo desencadeou a implementação das diretrizes sobre a avaliação, acrescentando ao conjunto de legislações a nova Lei de Diretrizes e Bases da Educação Nacional, Lei no 9.394/1996, oficializando novos mecanismos: o Exame Nacional de Cursos (ENC), realizado por concluintes de cursos de graduação; o questionário sobre as condições socioeconômicas do aluno e suas opiniões sobre as condições de ensino do curso frequentado; a Análise das Condições de Ensino (ACE); a Avaliação das Condições de Oferta (ACO); e a Avaliação Institucional dos Centros Universitários (INEP, 2009). 
Com a legislação em destaque, vários instrumentos normativos foram oficializados a fim de gerar diagnósticos relativos à educação superior, destacando-se o papel do ENC, considerado um retrocesso no discurso construído em torno de uma avaliação preocupada com as finalidades sociais das IES. Nesses aspectos, o ENC "[...] preocupa-se com a produtividade, a eficiência, com o controle do desempenho frente a um padrão estabelecido e com a prestação de contas" (INEP, 2009, p. 20).

Das tendências que se apresentam no estado da arte da avaliação, duas têm se revelado nos programas apresentados pelo governo de forma bem distinta: uma comprometida com a transformação acadêmica, em perspectivas formativas/emancipatórias, e a outra ligada ao controle, com concepções regulatórias. Assim, surge a relevância de apresentar estudos no campo da avaliação institucional com propósitos reveladores de seus impactos nos resultados obtidos, principalmente tendo como foco as concepções das tendências avaliativas que encaminharam os trabalhos de avaliação junto às IES, proporcionando indicadores de avaliação cujas concepções geram resultados positivos em relação às políticas de gestão institucionais. Rothen destaca a questão da qualidade da avaliação:

Ressalta-se, aqui, que a diferença básica entre duas vertentes é a instância na qual ocorre a definição do que é qualidade. $\mathrm{Na}$ visão neoliberal, os técnicos das agências estatais é que definem o que é qualidade bem como os indicadores a serem utilizados para aferi-la. Por sua vez, na avaliação participativa e emancipatória, a definição da qualidade e dos indicadores é negociada com os agentes do processo (2006, p. 108).

O enfoque a ser adotado deve ser considerado em relação às finalidades a que o processo avaliativo se direciona, pois se entende que a avaliação institucional não deve ser um processo com um fim em si mesmo, mas parte de um conjunto de políticas públicas para educação superior, voltadas para a expansão do sistema pela democratização do acesso, para que a qualidade dessa educação se reflita no desenvolvimento da nação brasileira. O Governo Lula, a partir de 2003, instituiu a Comissão Especial de Avaliação (CEA), com o objetivo de realizar estudos e propor um novo sistema de avaliação da educação superior. Essa comissão ainda tinha sob sua responsabilidade mediar as questões apontadas por diversos especialistas, na tentativa de equilibrar as concepções da avaliação que se revezavam nos programas anteriores. Porém, essa comissão tinha, em seus pressupostos, a marcada concepção emancipatória/formativa da avaliação, e apresentou um estudo que gerou a Lei $\mathrm{n}^{\mathrm{0}}$ 10.861/2004, instituindo o Sinaes.

Nas discussões em torno da aprovação ou não do Sinaes, conflitos se instalaram em relação ao papel que a avaliação deveria desempenhar: formação ou regulação. Segundo Rothen (2006), a citada lei priorizou a finalidade de regulação, dan- 
do início a uma avalanche de críticas ao Sinaes, o que provocou questionamentos acerca das suas finalidades. Destaca-se um dado importante apontado por Rothen:

Em todo processo de instalação e implantação dos SINAES, é presente a tensão entre os dois papéis da avaliação: em alguns momentos, a ênfase ocorre na formação/emancipação e, em outros, na regulação/controle. A partir desse ponto, retomar-se-á os diversos documentos oficiais (lei, decretos, proposta, diretrizes), buscando compreender, por um lado, o movimento das ideias e, por outro, o resultado dos arranjos políticos (2006, p. 115).

O Sinaes se tornou motivo de discussão dos estudiosos, os quais destacavam a necessidade de definição das funções da avaliação expressas em suas finalidades. A CEA elaborou significativos estudos acerca da posição que a avaliação deveria assumir no Sinaes e, em seu relatório considerou a avaliação, na proposta do Sistema Nacional de Avaliação, como "[...] um processo que procede sem desdobramentos, de natureza controladora, pois a universidade é autônoma, compete a ela avaliar-se, prestar contas à sociedade e melhorar a qualidade das suas atividades técnico-científicas" (BRASIL, 2003, p. 94).

A Lei $\mathrm{n}^{\circ}$ 10.861/2004 contraria o relatório da CEA. Na análise de Rothen (2006), o texto da citada lei a caracteriza como elemento de regulação do Estado, quando considera os resultados da avaliação referencial para o processo de regulação e supervisão da educação superior. Para o autor, a avaliação deve ter um papel além dos indicadores regulatórios, ou seja, um papel formador de novas políticas públicas para a educação superior, com o objetivo de gerar debates dentro e fora dos muros das IES, impulsionando-as à emancipação.

Contudo, apesar desse cenário de discussão e reflexão em torno de experiências, como a criação do Paru (em 1983) e do Programa de Avaliação Institucional das Universidades Brasileiras (Paiub) (em 1993), considera-se que suas experiências não foram duradouras e não construíram uma cultura da avaliação nas IES. Não obstante o quadro de instabilidade nas políticas de avaliação da qualidade da educação superior no Brasil, o MEC não hesitou em organizar uma comissão que se dedicasse aos estudos da avaliação. Isso provocou, em 14 de abril de 2004, no então governo do presidente Luiz Inácio Lula da Silva, a promulgação da Lei $n^{0} 10.861$, da Presidência da República, que instituiu o Sinaes.

Com a proposta de melhorar a qualidade e regulamentar as IES no âmbito da oferta da educação superior no Brasil, o Sinaes foi instituído atendendo a um rito como representação de um modelo de educação de qualidade aceito internacionalmente. O Sinaes apresenta as bases para as funções de regulação, ${ }^{14}$ supervisão ${ }^{15} \mathrm{e}$ avaliação ${ }^{16}$ exercidas pelos seguintes órgãos governamentais: MEC; Conselho Nacional de Educação (CNE); Inep; e Comissão Nacional de Avaliação da Educação Superior (Conaes), instituída pelo Decreto n⿳o 5.773, de 9 de maio de 2006. 
A partir do Sinaes, pretendeu-se subsidiar os atos regulatórios de autorização, ${ }^{17}$ reconhecimento ${ }^{18}$ e renovação de reconhecimento ${ }^{19}$ de cursos superiores. Para tanto, obedecendo a uma normatização que impõe ritos a todos os atores envolvidos no processo, a avaliação do Sinaes compreende os seguintes processos de avaliação institucional: avaliação interna das IES - autoavaliação; ${ }^{20}$ avaliação externa da educação superior - visita da comissão ad hoc do Inep; avaliação dos cursos de graduação - visita da comissão ad hoc do Inep; e avaliação do desempenho acadêmico dos estudantes de cursos de graduação - Exame Nacional de Desempenho de Estudantes (Enade).

No que diz respeito à proposta teórico-metodológica do Sinaes, elaborada pela CEA, ${ }^{21}$ a ideia central que permeia a proposta de uma política de avaliação da educação superior é a de integração e participação, na perspectiva de uma avaliação que respeite a diversidade, a busca de autonomia, a afirmação da identidade, promovendo valores democráticos. Segundo a CEA, “[...] tratou-se de buscar a articulação de um sistema de avaliação com autonomia, que é própria dos processos educativo-emancipatórios, e as funções de regulação, que são inerentes à supervisão estatal, para o fortalecimento das funções e compromissos educativos" (INEP, 2009, p. 91).

\section{Algumas questões}

A preocupação em atender a modelos de qualidade impostos de fora para dentro contamina também o Sinaes, no Brasil. O contexto em que o Sinaes surge revela um movimento oriundo do expansionismo da oferta da educação superior, gerando questionamentos em torno da qualidade da oferta desse ensino, porém não se reduz a essa questão da qualidade. Para além de fronteiras, a educação superior, sob o discurso da qualidade, gera influência mercadológica na estrutura e na dinâmica da oferta do ensino em IES - públicas ou privadas -, revelando motivações que mobilizam estruturas políticas e econômicas em prol do asseguramento da qualidade da oferta da educação superior.

A questão da regulação e da emancipação presente nos processos de avaliação tem assumido contradições que se revelam na fala, na sutileza de discursos passivos de convivência harmoniosa. Assim caminham as políticas para avaliação da qualidade da educação superior na América Latina e no Brasil, em um quadro de contradições, em que modelos de regulação definem-se como políticas de "prestação de contas" - Accountability - produzindo sistemas de avaliação, visando buscar padrões de indicadores de rendimento, produtividade, mas com o "capuz" de um discurso de prestação de contas à sociedade. 
A prestação de contas (Accountability) impulsiona a implantação de sistemas de avaliação da qualidade como forma de estabelecer a confiança nas IES, não somente por parte das sociedades, mas também de investidores financeiros. Nesse cenário de contradições e lógica do capital financeiro, definindo políticas para educação superior, mobilizamo-nos a pensar em uma educação contra-hegemônica, em um processo que privilegie uma avaliação participativa.

A resposta contra-hegemônica que nos mobilizamos a pensar, nessa perspectiva de refletir os impactos dos sistemas nacionais de avaliação da qualidade da educação superior, encontra ressonância no paradigma de um modelo de avaliação participativa, em que estariam presentes os princípios: democracia direta, práxis política, participação dos sujeitos, universidade como bem público. Acrescentamos a esse rol que circunda essa concepção de avaliação participativa o respeito à diversidade regional e local.

\section{Notas}

1 Pesquisa com financiamento da Coordenação de Aperfeiçoamento de Pessoal de Nível Superior (Capes).

2 A Carta de Punta del Este foi um documento assinado, em 17 de agosto de 1961, pelos governos da América Latina e do Caribe, em reunião extraordinária do Conselho Interamericano, Econômico e Social ligado à Organização dos Estados Americanos, estabelecendo uma aliança para o progresso.

3 Consultor e membro da Usaid durante as décadas de 1950, 1960 e 1970. Foi encarregado de planejar a reforma de algumas universidades na América Latina, incluindo as do Brasil.

4 Ver Huberman (1979).

5 Expressão utilizada por Amaral (2003) para ilustrar o cenário do caso brasileiro no que tange a políticas para a educação superior, adotando, para a sobrevivência do ensino público, a compressão dos recursos financeiros por meio de lógicas e regras do mercado financeiro.

6 Ganhador do Prêmio Nobel em Ciências Econômicas, em 1960, Theodoro Schultz apresentou a teoria do capital humano: "A noção relativamente simples de que o ritmo do crescimento econômico e social dos países se deve, em grande medida, ao nível de escolarização de sua população e, portanto, que os gastos com a educação não são consumo, mas de investimento, se espalhou por todo mundo e deu início a uma nova era de otimismo e de expansão dos sistemas educacionais, sobretudo nos países em desenvolvimento" (BROOKE, 2012, p. 55).

7 Consultar Frigotto (2003), considerada uma obra nacional de crítica à teoria do capital humano.

8 Quadro de heterogeneização dos modelos de universidades, das fontes de financiamento de fundos diversos, da ampliação da oferta da educação superior em instituições privadas, da relação financiamento e resultados, do surgimento dos rankings, além da adequação de diretrizes do mercado mundial - FMI e BM.

9 Disponível em: <www.orgworldtradeorganization.org>. Acesso em: 19 dez. 2015.

${ }^{10}$ Declaração Mundial sobre a Educação Superior no século XXI - visão e ação (1998) foi o documento resultante das discussões na Conferência Mundial sobre a Educação Superior realizada pela UNESCO, em Paris, em 9 de outubro de 1995, documento disponível em português na Biblioteca virtual de Direitos humanos da Universidade de São Paulo. Disponível em: <http://www.direitoshumanos.usp.br>. Acesso em: 30 set. 2015.

${ }^{11}$ Disponível em: < em: 29 mar. 2015.

12 Disponível em: <www.cres.org>. Acesso em: 10 set. 2009.

${ }^{13} \mathrm{O}$ processo de Bolonha deve seu nome à chamada declaração de Bolonha, que foi assinada, em 19 de junho de 1999, na cidade de Bolonha (Itália), pelos ministros responsáveis pelo ensino superior de 29 países europeus. Trata-se de um processo de reforma intergovernamental que visa concretizar o espaço europeu 
de ensino superior. Este espaço está pensado para ser um espaço aberto que permita aos estudantes, aos graduados e ao pessoal especializado que trabalha na área do ensino superior se beneficiar de uma mobilidade e de um acesso equitativo, sem obstáculos, a um ensino superior de alta qualidade. Disponível em: <www.uc.pt/ge3s/pasta_guia_ge3s/proc_bolonha>. Acesso em: 12 fev. 2016.

${ }^{14}$ Realizada por atos autorizativos de IES e de cursos de graduação (credenciamento, recredenciamento, autorização, reconhecimento e renovação de reconhecimento) pelo MEC.

${ }^{15}$ Constante acompanhamento por parte do MEC, com o objetivo de zelar pela qualidade da oferta de educação superior no sistema federal.

${ }^{16}$ Processo formativo e referencial para a regulação e supervisão da educação superior, a fim de promover a melhoria de sua qualidade por meio de autoavaliação e visita in loco de avaliadores do Inep.

${ }_{17}$ A oferta de cursos superiores em faculdades e instituições depende da autorização do MEC.

${ }_{18}$ Ato de reconhecimento é condição essencial para a validação nacional do curso e expedição de diplomas.

${ }^{19}$ São processos constantes de verificação da regulação dos cursos dentro dos indicadores de qualidade.

${ }^{20}$ A autoavaliação compreende o processo de submeter à apreciação da comunidade universitária o diagnóstico da IES, dar voz aos interlocutores como docentes, discentes e pessoal técnico-administrativo.

${ }^{21}$ Portaria MEC/Sesu no 11, de 28 de abril de 2003, e nํ19, de 27 de maio de 2003 (INEP, 2009).

\section{Referências}

ALVES, G. Trabalho e munidalização do capital: nova degradação do trabalho na era globalizada. Londrina: Práxis, 1999.

AMARAL, N. C. Financiamento da educação superior: estado x mercado. Piracicaba, SP: Unimep, 2003.

BOSCHETTI, V. R. Plano Atcon e Comissão Meira Mattos: construção do ideário da universidade do pós-64. Revista HISTEDBR, Campinas, v. 27, p. 221-229, set. 2007.

BOURDIEU, P. Razões práticas sobre a teoria da ação. 11. ed. Campinas, SP: Papirus, 2011.

BRASIL. Relatório Sinaes: bases para uma nova proposta. Brasilia, DF: Inep, 2003.

BROOKE, J. Marcos históricos na reforma da educação. Belo Horizonte: Fino Trato, 2012.

BROVETTO, J. A Educação na América Latina: balanço e perspectivas. In: TRINDADE, H.; BLANQUER, J.-M. Os desafios da educação superior na América Latina. Petrópolis, RJ: Vozes, 2002. p. 345-356.

CONTERA, C. Modelos de avaliação da qualidade da educação superior. In: DIAS SOBRINHO, J.; RISTOFF, D. (Org.). Avaliação democrática: para uma universidade cidadã. Florianópolis, SC: Insular, 2002. p. 119-144.

FRIGOTTO, G. Educação e a crise do capitalismo real. 5. ed. São Paulo, SP: Cortez, 2003.

GUADILLA, C. G. Educación superior en América Latina: uma perspectiva comparada de la década de los noventa. In: TRINDADE, H.; BLANQUER, J.-M. Os desafios da educação na América Latina. Petrópolis, RJ: Vozes, 2002. p. 32-60.

HARVEY, D. Condição Pós-Moderna. 25. ed. Sao Paulo, SP: Loyola, 2014.

HUBERMAN, Leo. História da riqueza do homem. Rio de Janeiro, RJ: Zahar, 1979.

IANNI, O. A sociologia e o mundo moderno. Rio de Janeiro, RJ: Civilização Brasileira, 2011. 
INSTITUTO NACIONAL DE ESTUDOS E PESQUISAS EDUCACIONAIS ANÍSIO TEIXEIRA. Sinaes - Sistema Nacional de Avaliação da Educação Superior: da concepção à regulamentação. Brasília, DF: Inep, 2009.

LEITE, D. Avaliação institucional: reformas e redesenho capitalista das universidades. In: SOBRINHO, J. D.; RISTOFF, D. Avaliação e compromisso público: a educação superior em debate. Florianópolis, SC: Insular, 2003. p. 53-76.

Avaliação da educação superior. In: MOROSINI, M. C. Enciclopédia de Pedagogia Universitária. Brasília, DF: Inep/Ries, 2006. p. 461-506.

LEITE, D.; GENRO, M. E. H. Quo Vadis? Avaliação e internacionalização da educação superior. In: LEITE, D. et al. Políticas de evaluación universitária en América Latina: perspectivas críticas. Argentina: CLACSO, 2012. p. 15-30.

ORTIZ, R. Mundialização e cultura. São Paulo, SP: Braziliense, 2000.

RAMA, C. La tercera reforma de la educación superior en América Latina. Buenos Aires: Fundo de Cultura Económica de Argentina, 2006.

ROCHA, Dario do Carmo da. A Carta de Punta Del Este: as ideias positivistas nas reformas educacionais e no Plano de Segurança Nacional orquestradas na década de 60. 1961. Disponível em: <http://www.ebah.com.br/content/ABAAAAqbwAF/positivismo>. Acesso em: 04 dez. 2016.

ROSAS, P. Para compreender a educação superior brasileira. Rio de Janeiro: Paz e Terra, 1992.

ROTHEN, J. C. Ponto e contraponto na avaliação institucional: análise dos documentos de implantação do Sinaes. In: SILVA JR., J. R. S.; OLIVEIRA, J. F.; MANCEBO, D. (Org.). Reformas universitárias: dimensões e perspectivas. Campinas, SP: Alínea, 2006. p. 107-124.

SANTOS, M. Por uma outra globalização: do pensamento único à uma consciência universal. Rio de janeiro: Record, 2015.

SOBRINHO, J. Avaliação da educação superior. São Paulo: Vozes, 2000.

SOUSA SANTOS, B. Pela mão de Alice: o social e o político na pós-modernidade. São Paulo: Cortez, 2008a.

. A gramática do tempo: para uma nova cultura política. São Paulo: Cortez, 2008b.

. Um discurso sobre as ciências. 5. ed. São Paulo: Cortez, 2008c.

UNESCO. Informe mundial: hacia las sociedades del conocimiento. Paris: Ediciones UNESCO, 2005. 